growing conditions and the opening of the flowers (anthesis) tends to be constant. It would appear then that vernalisation produces no actual acceleration of flowering, since there is no reduction in the time elapsing between the moistening of the grain and the occurrence of flowering. The apparent acceleration is due to the reduction in the number of days in the growing post-vernalisation period.

There is a further interesting point. The number of leaves formed not only responds to chilling but also to length of day. The temperate cereals are described as long-day plants, for their ears emerge in long days. In the winter forms, however, flower-formation takes place much more rapidly in short days, while spring forms do not exhibit this need. The effect of chilling winter forms is to make them independent of short days, so that, like the spring forms, they will flower rapidly in long days.

We are still ignorant as to the action of vernalisation by cold. Is it a primary temperature effect on the plant processes, or does the low temperature merely act indirectly by keeping growth in check and so inducing a kind of semi-dormancy in which slow maturation processes go on without any morphological change?

\section{DARK VERNALISATION}

As has been already stated, the sub-tropical cereals, such as maize, sorghum and other millets, are attuned to the short days of the tropics, as are also cotton and the soybean, and have their flowering much delayed in long days. It has been discovered, however, that if the grain of sorghum or millet is kept in darkness for a period, the need for short-day illumination of the plant is removed. The grain must of course be soaked, but in contrast with the vernalisation of winter cereals a high temperature is required. The grain is given about 25 per cent of its weight of water and then kept in the dark for 5-10 days at a temperature of $27^{\circ}-29^{\circ} \mathrm{C}$. After this treatment the plants will flower in long days or even in continuous light; their cultivation can thus be extended to regions of long summer days. This is a considerable achievement and suggests that in such plants the absence of light is necessary for the occurrence of certain changes. What seems to be important is a certain 'dose of darkness'; when a sufficient measure has been given the plant is independent of further periods of night.

Some light has thus been thrown on the nature of photoperiodism and vernalisation by these studies of winter cereals, but the nature of the changes in the plant during the periods of darkness and chilling are still in the greatest obscurity. Two results of general interest, however, have come from these investigations of duckweed and winter cereals. One, the fact that physiological changes, which it is difficult to describe as other than development, can go on in a swollen, 'colddormant' seed incapable of growth. Secondly, there has been demonstrated the need for change if the plant is to run its full life-cycle. Duckweed may multiply best at a constant high temperature and continuous light, but for many plants when flowering is concerned, variation in the environment is essential. To them, one may say, uniformity is anathema. It is evident that this need for variety greatly complicates the physiological analysis of plant responses, for the effect of not one but many environments has to be investigated.

\title{
Medical Research in 1935
}

\begin{abstract}
$A S$ in previous years, perusal of the report of A the Medical Research Council* provides the reader with a broad view of the research work carried out in Great Britain in medicine and its allied subjects : from its pages, the trend of recent investigations can be quickly and easily followed. The increase in the grant-in-aid provided by Parliament enabled the Council to restore the cuts in salaries and to proceed with plans for new research work which had been temporarily in abeyance, and to undertake additional investigations required for the purposes of administrative

* Committee of the Privy Council for Medical Research. Report of the Medical Research Council for the year 1934-1935. (Cmd. 5079.) Pp. 183. (London: H.M. Stationery Office, 1936.) 38. net.
\end{abstract}

departments. Lord Dawson of Penn and Prof. A. E. Boycott retired from the Council, and Prof. J. A. Ryle and Prof. M. J. Stewart were appointed to succeed them. Towards the close of the period under review, the Council learnt of the impending retirement of its chairman, the Marquess of Linlithgow, on his appointment as Viceroy of India. The funds of the Council have been augmented as in previous years by sums of money for the promotion of particular schemes of research, provided by a number of different bodies. The Council is also responsible for the award of Rockefeller medical fellowships and Dorothy Temple Cross research fellowships in tuberculosis; the arrange- 
ment with the Rockefeller Foundation of New York will not, however, be renewed at the end of the present academic year, the fellows who are now abroad being the last to be appointed. The change is not due to any doubts as to the value of the scheme, or to any dissatisfaction with the results which have been achieved; but is due entirely to a fundamental change in policy of the Foundation, which involves abandonment of its present system of international fellowships in favour of concentration upon a more restricted programme for the promotion of research. The Council is concerned with the question of filling the gap in the system of higher medical education caused by the withdrawal of these fellowships; meanwhile, the trustees of the late Viscount Leverhulme are providing funds, for the next five years in the first instance, for the award of one travelling fellowship annually.

The report refers to the practical application of the newer facts of nutrition, and emphasises that, at any rate until recently, the public was unaware of the importance of proper feeding as a factor in preventive medicine. It reviews some of the more practical discoveries which the Council has assisted during the period of its existence. Of these, probably the most important is the discovery and finally the isolation of vitamin $\mathrm{D}$, with the proof of its curative and preventive action in rickets and dental disease. Other investigations have shown the good effects of supplementing the diet of growing children with milk and other substances, and have demonstrated the incidence of nutritional anæmia in pregnant and lactating women and in their infants, and shown how the condition can be avoided or mitigated. Still, even at the present time, only a small fraction of the people have reaped the benefits that modern knowledge of nutrition can offer: the essential teachings can, however, be reduced to a few simple statements. The first is that the younger the child the more essential is correct feeding for proper growth and health : and the second, that much more milk, cheese, butter, eggs and green vegetables ought to be consumed ; milk ought to be the chief drink for children, while bread and other cereals should in these early years be greatly reduced.

Among the new substances which have been examined during the past year have been ergometrine, Dakin and West's hæmatopoietic agent (anahæmin) and androsterone. The report reviews briefly the history of the chemistry and pharmacology of ergot; the apparent disparity between pharmacological evidence and clinical practice was not solved until Chassar Moir demonstrated the presence in a watery extract of the drug of a substance stimulating, when given by the mouth, the human puerperal uterus; none of the known constituents of ergot had this effect, and the new alkaloid was finally isolated by Dudley and himself in crystalline form and called ergometrine. The substance prepared from liver by Dakin and West, which has a complex protein structure made up of amino-acid and other groups, has been manufactured in Great Britain, and submitted to clinical trial by Davidson, Wayne and Ungley on cases of pernicious anæmia. The substance thus prepared is extremely potent : injections of from $0.1 \mathrm{gm}$. to $0.2 \mathrm{gm}$., once weekly, brought about a large increase in the red blood corpuscles of the patients and in the course of a few weeks restored them to health. Analysis of the death-rates from this disease shows that the therapy has appreciably extended the lives of patients suffering from it.

Viruses and virus-like infective agents have con. tinued to occupy a prominent position in the programme of research at the National Institute for Medical Research. The possibility of obtaining from human cases of epidemic influenza a virus infecting the ferret, and transmissible then to other ferrets and to mice, as mentioned in last year's report, has been abundantly confirmed, although direct transmission from man to mouse has not yet been attained. A certain method of producing complete immunity to the experimental infection has not yet been found, although resistance can be significantly enhanced in either ferrets or mice, by subcutaneous injection of the living virus, which is not infective when thus applied, or of a formolised vaccine prepared from it. A serum neutralising the infective activity of the virus has been prepared by immunising a horse : injections into infected mice have given results which suggest that such a serum might have some value in the treatment of influenzal pneumonia. The virus has been shown to multiply on the chorio-allantoic membrane of the developing chicken and in a saline medium containing fragments of surviving tissue from a chicken embryo. The latter method has also been successfully employed in the cultivation of the viruses of psittacosis, ectromelia, vaccinia and louping ill.

Among other researches which have a close relationship to the public health may be mentioned the work on methods of preventing puerperal sepsis, on industrial pulmonary disease and the toxicity of industrial solvents and on methods of eradicating bed-bug infestation. The use of the new technical procedures which have been developed in recent years for differentiating the hæmolytic streptococci has led to the conclusion that the organisms which are occasionally found in the genital tract of healthy parturient women are not, as was formerly supposed, identical with those causing puerperal fever, and are indeed 
usually harmless to their human hosts. The pathogenic types which do invade the genital tract have therefore been conveyed to it from some outside source, for example, the respiratory tract, either of the mother or that of her attendants: familial sources have been incriminated in not a few instances. The results and lessons of that work, if rightly applied, should achieve a reduction in the incidence of hæmolytic streptococcus infection following childbirth.

In conclusion, reference may be made to the work of the Department of Biological Standards at the National Institute for Medical Research. Standards for gas gangrene antitoxins (vibrion septique and $B$. oedematiens), staphylococcus antitoxin and antipneumococcus serum (Types I and II) have been brought into official use under the
Therapeutic Substances Act. A new sample of diphtheria antitoxin standard has been prepared. The British standard for pituitary posterior lobe extract has now been adopted formally for international use. The Institute has also accepted responsibility for the preparation and distribution of the international standards for the arsphenamine group of drugs. New standards for a number of other compounds have been adopted for international use and have been distributed, or will be distributed as soon as prepared, namely, insulin, the vitamins (A, C and D) and the sex hormones (œstradiol benzoate, androsterone and progesterone). The supply of progesterone is being undertaken by the Institute : it is being prepared from pregnandiol and stigmasterol, and extracted from the corpora lutea of whales.

\section{Obituary}

\section{Dr. Arthur Eastwood}

$\mathrm{O}^{\mathrm{N}}$ May 6, after a few hours of illness, Arthur Eastwood, formerly of the Laboratory of the Ministry of Health, died in London in his sixty-ninth year. He was born in Manchester, was educated in its Grammar School and graduated in Lit. Hum. at Oxford in 1893. Deeply read in moral philosophy, with the Bar as the obvious place for his acute intellect and power of lucid exposition, Eastwood at this time fell under the spell of Michael Foster as the 'philosopher in medicine', migrated to Cambridge to sit at Foster's feet and finally qualified M.D. (London) in 1902, after clinical studies at St. Bartholomew's Hospital. His distinguished work in the histology of malignant tumours led the Royal Commission on Tuberculosis to invite him to examine its experimental material. At the Commission's experimental farm in Stansted, Essex, in 1902-9, Eastwood spent seven busy and happy years, making with Cobbett and the brothers Griffith a highly successful 'team', one of the first to show how valuable team-work can be in ad hoc research.

The Commission's final report left undecided the question of tubercle bacilli of bovine origin as the cause of tuberculosis in children and, in 1909, Eastwood, at Newsholme's suggestion, was given the post of Inspector to the Local Government Board and asked to establish for the Board its first pathological laboratory, with the duty of investigating this question. The Board's laboratory, later the Laboratory of the Ministry of Health, begun thus as an almost accidental afterthought, developed under Eastwood's direction into a valued branch of the Ministry's medical department. Its activities were recounted and accorded due recognition in the Annual Report of the Chief Medical Officer for 1932. They can be summarised as studies in the bacteriology of epidemics, ranging from bubonic plague (the epizootic in East Anglia in 1910) and cerebrospinal fever (the epidemies of the War years) to pneumococcus and streptococcus infections and directing attention to the significance, practical and theoretical, of serological 'types' in pathogenic bacterial species.

In all these researches Eastwood's clear vision and gift of lucid expression were put at the service of his colleagues. He himself, though, of course, convinced of the prime necessity of experiment in scientific medicine, felt his own true bent to be the philosophical examination of first principles, the synthesis of experimental data into theory and the enunciation of hypotheses worthy of experimental test. A long series of articles, published as Reports to the Ministry or in the Journal of Hygiene, was the result. In these, he discussed infection and immunity as parts of the physiology of bacterial cells on one hand and animal hosts on the other. His method was almost Socratic in its simplicity and reliance on pure logic: his articles, whatever may be their ultimate value in advancing knowledge, will continue to delight all who take pleasure in intellectual disquisition. Perhaps the most notable example is his treatment of bacterial variation and transmissible autolysis (Reports on Pub. Health and Med. Subjects, 1923, No. 18) in which he put forward the hypothesis of non-viable mutants as the explanation for the phenomena associated with bacteriophage.

Eastwood's three years of leisure after retirement were devoted to the preparation of a conspectus of immunity in general; he felt that the importance of a unifying hypothesis for the great body of dis. parate data was not sufficiently appreciated by postEhrlich pathologists. It is to be hoped that this had reached a stage permitting of its publication as a final example of Eastwood's method. 